\title{
El exceso ritual manifiesto en el recurso de revocación fiscal
}

\section{The manifest procedural ritualism in the tax administrative appeal for revocation}

\author{
Luis EduARdo VÁzQuez CÁRDENAS
}

Universidad de La Salle Bajío/Universidad Iberoamericana León, México

$$
\text { https://doi.org/10.36105/iut.2021n34.05 }
$$

Recibido: $18 / 11 / 2021$

Aceptado: 10/12/2021

\section{RESUMEN}

Desde su concepción en la jurisprudencia argentina, la doctrina del exceso ritual manifiesto ha influido en la impartición de justicia en diversos países, incluyendo a México. Aunque la jurisprudencia mexicana no utiliza habitualmente la expresión "exceso ritual manifiesto", ha adoptado por diversas vías la doctrina propia de dicha figura. Dicha doctrina permite identificar el apego excesivo, mecánico o desproporcionado a las normas procedimentales. Entre los medios de defensa en materia fiscal, el recurso de revocación destaca por haberse creado con la intención expresa de privilegiar el fondo sobre la forma y de reducir formalismos. Sin embargo, todavía existen disposiciones y aplicaciones ritualistas de las reglas del procedimiento que contradicen esa finalidad.

Palabras clave:

exceso ritual manifiesto, recurso administrativo, prevalencia del derecho sustancial, debido proceso, principio pro actione.

Abstract:

Since its inception in Argentine jurisprudence, the doctrine of manifest procedural ritualism has influenced the administration of justice in various 
countries, including Mexico. Although Mexican jurisprudence does not typically use the expression "manifest ritual excess," it has adopted the doctrine itself in various ways. This doctrine is useful to identify excessive, mechanical, or disproportionate adherence to procedural rules. In the realm of tax controversies and the corresponding remedies, the appeal known as "revocation" stands out for having been created with the express intention to privilege substance over form, and to cut red tape. However, there are still ritualistic provisions in place, as well as a tendency toward ritualistic enforcement that contradict such purpose.

Keywords:

manifest procedural ritualism, administrative appeal, substantive law's primacy over procedural law, due process, pro action principle.

\section{Introducción}

Para quien desea justicia, las formalidades llegan a parecer obstáculos caprichosos. El anhelo de contar con caminos más directos y flexibles hacia la solución de una controversia es inseparable de la existencia misma de los procesos.

Una de las primeras alternativas que ofrecieron las leyes mexicanas a los procesos y sus formalismos fueron los recursos administrativos, como el de revocación fiscal. Sin embargo, la intención de crear recursos sencillos, rápidos y accesibles encontró como límite la necesidad de preservar la seguridad jurídica. Si el procedimiento se vuelve imprevisible, el propio particular no sabrá a qué atenerse en última instancia, por más que se haya visto favorecido en alguna etapa. Por consiguiente, el diseño normativo del recurso solo puede apartarse hasta cierto grado de las formalidades típicas: el recurso debe tramitarse "en forma de juicio".

La principal arma para abatir el formalismo en los recursos administrativos, pues, no radica en la redacción de la ley, sino en la interpretación y aplicación de ésta. Para ello, nuestro sistema jurídico reconoce técnicas y principios no formalistas, especialmente a partir de la reforma constitucional de 2017 que consagró el principio de prevalencia del derecho sustancial sobre las formas. Para cumplir con dicho mandato, las autoridades administrativas encargadas de resolver recursos deben evitar la aplicación mecánica o rigorista de las reglas formales, procurando la solución de fondo de la controversia conforme a la verdad objetiva.

Sin embargo, las doctrinas que permiten justificar decisiones en flexibilidades razonables son, hasta ahora, más propias de la formación y la técnica de los órganos propiamente jurisdiccionales; es decir, su aplicación es natural para los jueces, pero no para las autoridades administrativas. Esta circunstancia, aunada a la reciente implementación de nuevas formalidades de corte tecnológico en la tramitación del recurso de revocación, han derivado en que éste retroceda hacia el ritualismo. 
En el presente trabajo se delinean las características principales de la doctrina del exceso ritual manifiesto, como figura que permite llevar a la práctica la regla de poner el fondo sobre la forma, usando las formalidades como medios para mantener el orden en el proceso, siempre que aquellas sean razonables. Enseguida, se relaciona dicha doctrina con el recurso de revocación fiscal, a la luz de los principios que lo identifican. Finalmente, se examinan algunos resabios ritualistas del recurso para ejemplificar la falta de razonabilidad en que se incurriría de aplicar las formalidades de manera mecánica e inflexible.

\section{Doctrina del exceso ritual manifiesto y su adopción en México}

\section{Origen del concepto}

El 18 de septiembre de 1957, la Corte Suprema de Justicia de Argentina dictó su fallo número 238:550, correspondiente al caso Colalillo Domingo vs. Compañía de Seguros España y Río de la Plata, ${ }^{1}$ generalmente conocido como Colalillo. Para Bertolino, ${ }^{2}$ este precedente es tan relevante que la totalidad de la jurisprudencia relativa al exceso ritual manifiesto no es más que una "expansión y profundización" de lo allí resuelto.

¿Por qué es importante Colalillo? En esencia, se trató de un juicio por daños y perjuicios motivado por un accidente de tránsito. Uno de los temas a decidir fue si, a la fecha del accidente, el conductor involucrado tenía "registro habilitante" - equivalente a lo que hoy denominaríamos licencia para conducir- en virtud de que aquel manifestó haber extraviado el carnet oficial. La sentencia de primera instancia determinó que no prosperó la acción intentada por el actor, por no haber comprobado la existencia del registro habilitante. Sin embargo, antes de notificarse dicha sentencia a las partes, el actor presentó una promoción en la cual manifestó que, tras no haber recibido respuestas oportunas de la autoridad de tránsito sobre la vigencia de su registro original, finalmente solicitó y obtuvo un duplicado, del cual se desprendía que el original había sido expedido dos meses antes del accidente. El juez de primera instancia determinó notificar la sentencia en los términos que había sido originalmente dictada, a pesar del documento superveniente aportado por el actor. En la segunda instancia, la Cámara de Apelaciones confirmó el fallo, por considerar que la evidencia del registro habilitante se agregó extemporáneamente a los autos del juicio de origen, después de haberse dictado la sentencia.

Esa fue la controversia planteada ante la Corte Suprema en el recurso extraordinario. En una breve sentencia, la Corte concedió que corresponde a los interesados probar los hechos en que se apoye su acción y esa oportunidad probatoria tiene límites de tiempo y forma, pues, de no ser así, los juicios no tendrían fin. ${ }^{3}$ Esto es, las normas formales intervienen para evitar que la negligencia

\footnotetext{
Corte Suprema de Justicia de la Nación Argentina, Colalillo, Domingo c/ Compañía de Seguros España y Río de la Plata, fallos 238:550; LL 89-412; JA 1957-IV-477, fallo del 18 de setiembre de 1957.

2 Bertolino, Pedro, El exceso ritual manifiesto, 2a. ed., La Plata, Librería Editora Platense, 2003, p. 50.

3 Ibidem, p. 52.
} 
procesal de las partes rompa la igualdad durante el proceso. No obstante, la Corte sostuvo que el proceso civil no puede ser conducido en términos estrictamente formales ni sirve a "ritos caprichosos", sino que debe dirigirse permanentemente a descubrir la verdad jurídica objetiva. En particular, consideró que, en la sentencia de primera instancia de Colalillo, el juzgador renunció conscientemente a la verdad, al haber excluido de su fallo la prueba del hecho central de la controversia — el duplicado del registro habilitante - y limitar su análisis a la cuestión de extemporaneidad en la presentación del documento. Lo anterior, a ojos de la Corte, fue una conducta incompatible con el servicio de la justicia.

\section{Contenido y alcance de la figura}

Carrió identificó a Colalillo como caso paradigmático, dado que la Corte “creó pretorianamente una importante excepción general al principio de que las normas procesales rígidas no reconocen otras excepciones que las que su texto expresa" . ${ }^{4}$ En efecto, en el fallo citado, se argumenta que, de permitirse a los jueces renunciar a esclarecer de los hechos debatidos, "la sentencia no sería aplicación de la ley a los hechos del caso, sino precisamente la frustración ritual del derecho". ${ }^{5}$

El desdoble, pues, de la doctrina del exceso ritual manifiesto se dio en la jurisprudencia argentina. Bertolino hace notar que se le conoció con diversos nombres, ${ }^{6}$ tales como ritualismo, formulismo, rigor excesivo o injustificado rigor; pero todos ellos se refieren al mismo fenómeno: la mala utilización, desnaturalización o el abuso de las formas; en el sentido de no adecuación a la finalidad para la que ellas se han establecido.

Lo "manifiesto", para el propio Bertolino, radica en que el exceso resulte evidente y no requiera un juzgamiento previo para percibirlo. ${ }^{7}$ Lo "excesivo", en palabras de la Corte Suprema de Colombia, radica en aplicar las normas formales atendiendo únicamente a su texto o haciendo una aplicación mecánica de ellas; ${ }^{8}$ es decir, una aplicación tan rigurosa que aleja al juzgador de la verdad jurídica objetiva. Finalmente, lo "ritual" remite a incurrir en un culto en las formas; esto es, valorarlas como un fin en sí mismo y no como un medio para ordenar el proceso y encaminarlo hacia la verdad.

Como ya se dijo, no se trata de una exención de las formalidades ni de reducir éstas a meras guías de conducta durante el proceso. Carrió entiende al exceso ritual manifiesto como una manifestación del principio Summum ius summa iniuria (un derecho de contenido excesivo configura una injusticia intolerable)

4 CARrió, Genaro R., "Exceso ritual manifiesto y garantía constitucional de la defensa en juicio", Revista del Centro de Estudios Constitucionales, núm. 7, 57-77, julio-diciembre, España, 2018, p. 60.

Ibidem, p. 62.

Bertolino, Pedro, op. cit., p. 36.

Ibidem, p. 25.

Cfr. Caicedo Villamizar, Alexander E. "El exceso ritual manifiesto y la visión constitucional de la actividad judicial", Justicia, núm. 32, 79-117, julio-diciembre, Barranquilla, Universidad de la Costa, 2017, p. 98. https://doi.org/10.17081/just.23.32.2907 
-opuesto al axioma Dura lex sed lex - en cuanto a que todas las reglas procesales admiten excepciones o atenuaciones en casos particulares, cuando sea indispensable para resolver con equidad y justicia. ${ }^{9}$ Con ideas similares, García y Acevedo apuntan que la doctrina del exceso ritual expresa la posibilidad que tienen los jueces de decidir contra el tenor literal de una norma en casos especiales. ${ }^{10}$

Así pues, el rito procesal - equivalente a las formalidades y presupuestos procesales - no limita, por sí mismo, los derechos de las partes. Las formas, según Gozaíni, son parte de la lógica interior del proceso, de un modelo construido para que las partes puedan debatir en igualdad de condiciones y con seguridad jurídica. ${ }^{11}$ Luego, el exceso ritual surge de la tensión entre las formas indispensables y la búsqueda de un pronunciamiento de fondo que responda a la verdad objetiva, no a ficciones. Chiovenda, citado por Bertolino. ${ }^{12}$ reflexiona que la sociedad quiere, por una parte, que las formas sean pocas, simples y rápidas; pero, al mismo tiempo, necesita que esa simpleza no limite la discusión de las razones de las partes, en un equilibrio que el propio Bertolino expresa así: lo razonable es el 'rito'; lo irrazonable es el 'ritualismo' o exceso o abuso del rito. ${ }^{13}$ Con similares ideas, Flores señala que, sin el respeto a las formas, los procesos mismos serían arbitrariedades carentes de orden. ${ }^{14}$ Por eso, la doctrina del exceso ritual manifiesto se centra, en buena medida, en la búsqueda de las llamadas flexibilidades razonables.

En México, el propio Flores ha definido al exceso ritual manifiesto como el "defecto jurisdiccional que implica una renuncia consciente de la verdad jurídica objetiva, por un extremo rigor en la aplicación de una norma, sacrificando así cuestiones sustanciales que repercuten en una denegación de derechos". ${ }^{15}$ En la alusión a la renuncia consciente de la verdad jurídica objetiva, encontramos un eco de la sentencia de Colalillo.

En cuanto elementos para que exista un exceso reclamable, en lugar de una justa consecuencia a la conducta procesal negligente del interesado, García y Acevedo, coinciden con Flores en tomar como referente la jurisprudencia de la Corte Suprema de Justicia de Colombia, por su prolífica generación de precedentes en la materia. En particular, los autores citados en primer término enuncian los siguientes requisitos: ${ }^{16}$

9 CARrió, Genaro R., op. cit., p. 74.

10 García, Pedro A. y Acevedo Prada, Milena, "La doctrina de la corte constitucional colombiana sobre el exceso ritual manifiesto en materia de pruebas", Vniversitas, 127-156, núm. 127, julio-diciembre, Bogotá 2013, p. 130.

11 Gozaíni, Osvaldo, A., "Funciones del juez en los procesos Constitucionales", Estudios Constitucionales, año 4, núm. 1, 299-332, México, Instituto de Investigaciones Jurídicas UNAM, p. 316.

12 Cfr. Bertolino, Pedro, op. cit., p. 84.

13 Ibidem, p. 126.

14 Flores Ayvar, Lawrence, "El exceso ritual manifiesto", en Godínez MÉndez, Wendy y García PeÑa, José H. (coords.), Temas actuales del derecho. El derecho en la globalización, México, Instituto de Investigaciones Jurídicas UNAM, 2014, p. 264.

15 Ibidem, p. 250.

16 Cfr. García, Pedro A. y Acevedo Prada, Milena, op. cit., p. 137 

a) Apego excesivo a las normas procedimentales;
b) Renuncia consciente y manifiesta del juzgador a la búsqueda de la ver- dad objetiva;
c) Negación de la prevalencia del derecho sustancial (poner forma sobre fondo), y
d) Vulneración de algún derecho fundamental.

Finalmente, siguiendo las ideas de Flores, los casos concretos en los cuales puede configurarse un exceso ritual se pueden agrupar en tres rubros: ${ }^{17}$

i. Aplicación de disposiciones que se oponen a la vigencia de derechos. Ocurre cuando se aplica conscientemente la consecuencia prevista en una norma procesal en detrimento de un derecho sustantivo; aun cuando aleje al juzgador de la verdad objetiva.

ii. Exigencia irreflexiva del cumplimiento de requisitos formales. Se presenta a través de la aplicación mecánica, no atenuada ni modulada, de las normas procesales; las cuales se convierten en barreras de entrada para la acción e impiden el pronunciamiento de fondo.

iii. Apreciación rigurosa de pruebas. Acontece, como en el caso Colalillo, cuando el juzgador desestima un medio probatorio que tiene a su alcance y es relevante al fondo del asunto, apoyándose exclusivamente en el incumplimiento de formalidades a cargo de la parte que la ofreció.

En un capítulo posterior identificaremos ciertos escenarios que pueden presentarse en un recurso administrativo, y encuadran en los rubros recién mencionados.

\section{Adopción en Latinoamérica y en México}

Entre los países que han adoptado la doctrina en trato, destaca Colombia. En el artículo 228 de la Constitución colombiana se conmina a que en la administración de justicia prevalezca el derecho sustancial. Esta disposición reconoce que el fin del proceso no es la exteriorización de sus formas, sino la realización de los derechos perseguidos, mediante la solución del conflicto de fondo. ${ }^{18}$ Por ello, la Corte Constitucional de Colombia ha generado amplia jurisprudencia en torno al exceso ritual; a partir de las bases sentadas en la sentencia T-1306 de $2001 .{ }^{19}$

En el caso de Ecuador, el artículo 169 de su constitución ofrece una fórmula sumamente clara: "no se sacrificará la justicia por la sola omisión de formalidades". En tanto que la Constitución de Panamá opta por consagrar los principios de simplificación de trámites, economía procesal y ausencia de formalismos.

\footnotetext{
17 Flores Ayvar, Lawrence, op. cit., pp. 253-264.

19 Ibidem, p. 95.
} 
En México, a partir de 2017, el artículo 17 constitucional dispone: "Siempre que no se afecte la igualdad entre las partes, el debido proceso u otros derechos en los juicios o procedimientos seguidos en forma de juicio, las autoridades deberán privilegiar la solución del conflicto sobre los formalismos procedimentales". Nótese la alusión a los "formalismos" y no meramente a las formas: la prohibición no recae sobre éstas, sino sobre su abuso.

En armonía con lo anterior, en la exposición de motivos para la reforma constitucional se postuló que el proceso es un medio para facilitar el reconocimiento de los derechos sustantivos, mientras que "hoy se confunde la aplicación de las normas con la impartición de justicia"; aunado a que "en la impartición de justicia en todos los niveles y materias, las leyes se aplican de forma tajante e irreflexiva, y no se valora si en la situación particular cabe una ponderación que permita favorecer la aplicación del derecho sustantivo por encima del derecho adjetivo". ${ }^{20}$ Lo cual equivale a las flexibilidades razonables que, como ya vimos, persigue la doctrina sobre el exceso ritual.

Sin embargo, antes de su incorporación al texto constitucional, dicha doctrina ya había sido adoptada por nuestros tribunales. Destaca la tesis de jurisprudencia 1a./J. 42/2007 de la Primera Sala de la SCJN, en la cual se condenan las normas que impongan "requisitos impeditivos u obstaculizadores", en la medida que se oponen al derecho a la tutela judicial, cuando resultan innecesarios, excesivos y carentes de razonabilidad o proporcionalidad respecto de los fines perseguidos. ${ }^{21}$ En aquel caso, la Sala precisó que son constitucionales los requisitos procesales que respeten el derecho a la tutela constitucional y, además, tiendan a preservar otros derechos o intereses; por ejemplo, el cumplimiento de los plazos legales, el agotamiento de los recursos ordinarios previos antes de ejercer cierto tipo de acciones, o el otorgamiento de fianzas y depósitos.

Ya encontrándose en vigor la reforma al artículo 17 Constitucional, la propia Primera Sala de la SCJN ratificó su postura al emitir la tesis 1a./J. 90/2017. ${ }^{22}$ donde explicó que son compatibles con aquel precepto las condiciones legislativas para el acceso a los tribunales, al igual que la regulación de vías y procedimientos mediante requisitos de procedencia. Como ejemplos de formalismos aceptables, la Sala citó los relativos a: (i) la admisibilidad de un escrito; (ii) la legitimación activa y pasiva; (iii) la representación y personalidad; (iv) la oportunidad en la interposición de la acción, excepción, recurso o incidente; (v) la competencia del órgano ante el cual se promueve; (vi) la exhibición de documentos de los cuales depende la existencia de la acción, y (vii) la procedencia de la vía.

A pesar de la amplitud de los requisitos y formalidades que la Sala consideró aceptables a priori en la tesis 1a./J. 90/2017, tuvo el cuidado de señalar que debe tratarse de los mínimos necesarios para "la realización de la jurisdicción";

20 Gaceta Parlamentaria, número 4769-XX, 28 de abril de 2017, p. 18.

21 Tesis 1a./J. 42/2007, Semanario Judicial de la Federación y su Gaceta, Novena Época, t. XXV, abril de 2007, p. 124.

22 Tesis 1a./J. 90/2017, Gaceta del Semanario Judicial de la Federación, Décima Época, Libro 48, noviembre de 2017, t. I, p. 213. 
esto es, para que el juzgador pueda conocer la cuestión de fondo y resolverla. Con el fin de determinar si se trata de elementos mínimos, la propia Sala consideró indispensable un análisis caso a caso, para corroborar que no existan impedimentos jurídicos o fácticos carentes de racionalidad o proporcionalidad, o bien - agregó posteriormente - que resulten discriminatorios.

Finalmente, en una tesis más reciente (1a./J. 58/2019 (10a.)), la misma Primera Sala de la SCJN invocó expresamente la figura del exceso ritual manifiesto. ${ }^{23}$ Al examinar el requisito de cercioramiento del domicilio durante las diligencias de emplazamiento en juicios civiles, la Sala estimó innecesario que los actuarios describan a la persona que les informó a quién correspondía el domicilio, cuando dicha persona se niegue a dar su nombre, identificarse o firmar. Lo anterior, porque la imposición a los actuarios de aspectos difíciles o imposibles de lograr, de manera que se invalidara la actuación solo por no haber dado razón de alguna o algunas de las características físicas del sujeto, "representaría un exceso ritual manifiesto en que se privilegiaría la forma por sí misma, y no por su objetivo, con lo cual, paradójicamente, se vulneraría el debido proceso y el acceso a la justicia". ${ }^{24}$

\section{Relación con otros principios del sistema jurídico mexicano}

Badillo señala con acierto que la problemática del rigor excesivo es una sola, mientras que las denominaciones para designarla son distintas: ${ }^{25}$ ritualismos, impedimentos no razonables, formalismos desproporcionados, requisitos impeditivos u obstaculizadores, etcétera. La terminología predominante en la jurisprudencia mexicana ha sido la gestada en las resoluciones de la Corte Interamericana de Derechos Humanos (Corte IDH). A manera de ejemplo, dicha Corte falló en el Caso Trabajadores Cesados del Congreso (Aguado Alfaro y otros) Vs. Perú, que los recursos internos deben resolver efectivamente el asunto planteado; sin que por ello se pueda afirmar que los tribunales siempre deban resolver el fondo, toda vez que, por razones de seguridad jurídica, deben verificar que se cumplan los presupuestos de admisibilidad y procedencia. ${ }^{26}$ Estas premisas son similares a las esgrimidas por la Primera Sala de la SCJN en las tesis jurisprudenciales ya reseñadas.

Por ello, los tribunales mexicanos han combatido el exceso ritual manifiesto a partir de varias "técnicas judiciales no formalistas", como las llama Serrano. ${ }^{27}$ El mismo autor recopila los postulados del Tribunal Constitucional español que

23 Tesis 1a./J. 58/2019, Semanario Judicial de la Federación, Décima Época, Libro 48, viernes 11 de octubre de 2019 10:21 h.

24 Idem.

25 Badillo García, Armando A., "El juicio de amparo y sus formalismos procedimentales: Algunas notas sobre el papel de los jueces de distrito", Revista del Instituto de la Judicatura Federal, núm. 45, enero-junio, México, 2018, pp. 5-7.

26 Corte IDH, Caso Trabajadores Cesados del Congreso (Aguado Alfaro y otros) Vs. Perú, sentencia de 24 de noviembre de 2006. Serie C No. 158.

27 Serrano Hoyo, Gregorio, "Formalismo y tutela judicial efectiva en la jurisprudencia del Tribunal Constitucional", Anuario de la Facultad de Derecho, núm. 10, 119-168, España, Universidad de Extremadura, 1992, p. 132. 
dieron forma al principio pro actione o de interpretación más favorable a la prosecución del proceso. Este principio nace en la jurisprudencia como una regla hermenéutica que se opone a que los requisitos formales se conviertan en obstáculos injustificados para el pronunciamiento sobre el fondo. No obstante, como se pregunta el propio Serrano, si una norma expresa con claridad un requisito de forma, ¿hasta qué grado es posible interpretarla, sin que el juzgador incurra en cambiar la norma? ${ }^{28}$ Visto así, el principio de interpretación más favorable sería insuficiente para impedir que, en casos concretos, las formas nos alejen de la verdad material objetiva.

Por ello se amplió la concepción del principio pro actione para convertirlo en una regla de juicio sobre la aplicación de las normas formales en un caso concreto; pues la tutela judicial efectiva "no sólo exige que la interpretación de las normas procesales se inspire en el principio pro actione, sino que también ese principio inspire su aplicación". ${ }^{29}$ En esta dimensión, el principio ya incorpora la posibilidad de decidir contra el tenor literal de una norma en casos especiales, característica de la doctrina del exceso ritual manifiesto. Adicionalmente, el principio pro actione ha llegado a abarcar el enjuiciamiento de la exigencia legal en sí misma; es decir, la evaluación abstracta de su idoneidad, necesidad, razonabilidad y proporcionalidad, así como su conformidad con otros derechos fundamentales, de tal manera que pueda desaplicarse por mandado jurisdiccional.

Luego, el principio pro actione, en su acepción moderna, tiene alcances muy amplios. Por una parte, impone a los impartidores de justicia la obligación de optar por la interpretación que favorezca la solución definitiva de la controversia. Al mismo tiempo, exige flexibilidades razonables en la aplicación de las formalidades procesales, para evitar que su aplicación se vuelva obstaculizadora o impeditiva de la justicia en casos concretos (excesos rituales). De igual manera, guía el control jurisdiccional sobre las normas que imponen cargas formales, al confrontarlas con el derecho a la tutela jurisdiccional efectiva. Finalmente, funge como referencia en el diseño de las normas procesales.

En suma, si bien la jurisprudencia mexicana solo utiliza la expresión "exceso ritual manifiesto" esporádicamente, ha adoptado por diversas vías la doctrina propia de dicha figura. En nuestro país, el control sobre el ritualismo se ha enunciado a partir de figuras diversas, tales como los principios pro homine y pro actione; los mandatos de tutela jurisdiccional efectiva y debido proceso y las reglas para la interdicción de la arbitrariedad (razonabilidad, proporcionalidad, etcétera).

\section{Naturaleza y principios distintivos del recurso de revocación fiscal}

El recurso de revocación previsto en el Código Fiscal de la Federación (CFF) - comúnmente denominado de "revocación fiscal" - es un medio directo de control de legalidad de los actos de las autoridades fiscales. Es decir, se trata de un

28 Ibidem, p. 133.

29 Ibidem, p. 135. 
procedimiento administrativo que los particulares pueden iniciar ante la propia autoridad que emitió los actos que les ocasionen agravios en materia fiscal, con el fin de obtener una declaración sobre su ineficacia.

Así entendido, el recurso tiene como razón de ser el deber de buena administración. La autoridad administrativa desplegará una función revisora, con la peculiaridad de hacerlo en forma directa y rogada, pronunciándose sobre los agravios expresados por el particular directamente afectado. Los principales beneficios de esta función radican, para la Administración, en purgar sus expedientes de potenciales nulidades, cuya declaración en etapas posteriores ocasionaría una mayor pérdida de tiempo y recursos. Esta premisa la respalda la exposición de motivos de la iniciativa que daría lugar al decreto de reformas publicado el 6 de mayo de 2009; en la cual, los Senadores promoventes explicaron que "es la propia Administración la que está más interesada en depurar, revisar o modificar ese acto, antes de que sea objeto del control judicial". 30

Ahora bien, el carácter especializado de las controversias fiscales hizo de éstas terreno fértil para los recursos administrativos. Por ello, en 1925 existía ya un antecedente de recurso administrativo que podía agotarse ante las Juntas Calificadoras en materia del Impuesto sobre la Renta. ${ }^{31}$ La primera aparición del recurso de revocación se dio en los artículos 160 y 161 del CFF de 1967, como parte de un cuerpo de recursos que también comprendió el de oposición al procedimiento ejecutivo; el de oposición de tercero y la reclamación de preferencia (tercerías), así como la nulidad de notificaciones. En su versión incipiente, el recurso de revocación únicamente procedía en contra de resoluciones en las cuales se determinasen créditos fiscales; mientras que, en la actualidad, este recurso ha absorbido todos los que llegó a comprender el CFF de 1967. Por ende, el código tributario vigente establece un solo recurso administrativo: el de revocación.

\section{Tramitación por medios electrónicos}

Las reformas al CFF publicadas el 9 de diciembre de 2013 permitieron que el de revocación fuera el primer recurso administrativo en sustanciarse íntegramente en línea, sin conformar un expediente en papel. Fue el primer medio de defensa cuya tramitación por medios electrónicos se estableció en forma obligatoria, salvo en casos excepcionales.

La herramienta que posibilita el recurso electrónico es el "buzón tributario", un medio de comunicación individual entre las autoridades fiscales y los contribuyentes (aunque, inicialmente, solo fue empleado por el SAT), basado en la firma electrónica. Además de ser el medio primario para la notificación de actos fiscales, permite presentar promociones, depositar documentación y contestar requerimientos, entre otras funciones.

La exposición de motivos para la implementación del buzón tributario de uso obligatorio y, con ello, del recurso en línea, enfatiza la intención de que el

\footnotetext{
30 Gaceta del Senado, LX/3PPO-277/18329, 21 de octubre de 2008.

31 Armienta Hernández, Gonzalo, Tratado Teórico Practico De Los Recursos Administrativos, 9a. ed., México, Porrúa, 2013, p. 55.
} 
sistema tributario avance en la simplificación administrativa, con base en un aprovechamiento de la tecnología que evite el excesivo formalismo, sin dejar de fomentar el cumplimiento de las obligaciones fiscales. ${ }^{32}$ Así pues, los canales tecnológicos de uso obligatorio para los particulares que deseen promover el recurso no deberían traducirse en un incremento de formalismos, sino en una herramienta adicional para su abatimiento.

\section{Principios distintivos del recurso}

Ahora bien, Paz recoge la exposición de motivos para la creación del recurso de revocación en el CFF de 1967, destacando su concepción como un medio de defensa sencillo, con pocas formalidades y que puede ser utilizado por personas poco versadas en la legislación fiscal. ${ }^{33}$

El mismo autor también hace eco de la exposición de motivos del CFF de 1981, donde se recalcaron las finalidades de privilegiar el fondo sobre la forma y de reducir formalismos, "preservando sólo las formalidades necesarias para la seguridad jurídica de los contribuyentes". ${ }^{34} \mathrm{El}$ empleo de la voz formalismos en un contexto relativamente denostativo, así como la utilización del estándar de seguridad jurídica para modular la flexibilidad en las formas, son elementos distintivos de la doctrina del exceso ritual manifiesto. Esto es un indicio para afirmar que el diseño legislativo del recurso de revocación abrevó de dicha doctrina o, cuando menos, no la desconoció.

Así pues, al recurso de revocación lo caracteriza la aplicación de cinco principios; los cuales describimos siguiendo las ideas de Paz: ${ }^{35}$

a. De legalidad objetiva. Radica en que el recurso tiende a preservar la legalidad y la justicia en las decisiones de la autoridad administrativa.

b. De oficialidad. Consiste en la obligación de las autoridades encargadas de tramitar los recursos, de proveer el impulso y las gestiones necesarias para lograr el mejor conocimiento de los hechos y, así, poder emitir un pronunciamiento de fondo. Lo anterior se acota a las facultades de la autoridad resolutora para acordar la exhibición de cualquier documento o la práctica de cualquier diligencia que tenga relación con los hechos controvertidos, entre otras, sin que el procedimiento deje de ser a instancia de parte agraviada.

c. De la verdad material. Implica que la autoridad atienda a todos los elementos que tenga a su alcance para resolver; incluyendo aquellos que pueda recabar de oficio, o bien, a su propia convicción sobre la ilegalidad de los actos recurridos.

d. De debido proceso. Es la consecuencia de que el recurso sea un procedimiento administrativo seguido en forma de juicio. Esta característica

32 Gaceta Parlamentaria, número 3895-III, 29 de octubre de 2013.

33 PAz, Alejando, El Recurso de Revocación en Materia Fiscal, 4a. ed., México, Ediciones Fiscales ISEF, 2017, p. 31.

34 Idem.

35 Ibidem, pp. 49-54 passim. 
conlleva el deber de observar las formalidades esenciales del procedimiento, entre las cuales se encuentran: que el recurso sea tramitado y resuelto por una autoridad competente; que se otorgue al particular la oportunidad de formular agravios y la autoridad se pronuncie congruentemente sobre ellos; que se permita ofrecer y rendir pruebas; que se deje constancia escrita de todas las actuaciones; que sea ágil, sin trámites que dificulten su desarrollo; que el particular tenga una posibilidad efectiva de conocer todas las actuaciones administrativas, y que al recurso recaiga una resolución fundada y motivada.

e. De informalidad. Se manifiesta en el catálogo mínimo de requisitos para la formulación de escritos o la expresión de agravios; así como en la posibilidad de que los recurrentes sean prevenidos que subsanen cualquier omisión o deficiencia en que incurran, mientras no recaiga sobre elementos esenciales del recurso.

\section{El informalismo propio del recurso}

El principio de informalidad es el más distintivo del recurso de revocación fiscal frente a otros medios de defensa, como el juicio de nulidad. Bertolino se refiere al principio de informalismo como un rasgo diferenciador de la función administrativa respecto del proceso judicial. ${ }^{36}$ La informalidad o informalismo es consecuencia — según el autor citado - de la complejidad del quehacer de las administraciones estatales y de la necesidad de simplificar los trámites administrativos en general.

La correlación del informalismo del recurso con el resto de los principios que lo rigen - particularmente el de debido proceso - tiene un efecto equivalente a aplicar la regla del exceso ritual manifiesto. Es así, porque el recurso se dirige a la declaración de una verdad material y, en última instancia, a un pronunciamiento sobre la legalidad del acto recurrido, en un marco de previsibilidad guiado por las formalidades esenciales del procedimiento. Luego, el recurso de revocación es un procedimiento seguido en forma de juicio.

Como criterio rector sobre el concepto de los procedimientos seguidos en forma de juicio, destaca la jurisprudencia 2a./J. 22/2003, en la cual, la Segunda Sala de la $\mathrm{SCJN}^{37}$ los definió en sentido amplio como todos aquellos en que "la autoridad, frente al particular, prepara su resolución definitiva, aunque sólo sea un trámite para cumplir con la garantía de audiencia". Presenta forma de juicio, pues, todo procedimiento donde existan etapas o formalidades identificables, orientadas a que el administrado conozca la pretensión de la autoridad antes de la emisión del acto terminal o definitivo. ${ }^{38}$ Evidentemente, el recurso de revocación

36 Bertolino, Pedro, op. cit., p. 147.

37 Tesis 2a./J. 22/2003, Semanario Judicial de la Federación y su Gaceta, Novena Época, t. XVII, abril de 2003, p. 196.

38 En contraste, la acepción estricta o restrictiva del procedimiento administrativo en forma de juicio se limita al de tipo recursivo; esto es, aquel que busca tutelar, por la vía del control, los intereses particulares que afecte un acto administrativo, observando a las formalidades de oportunidad defensiva y oportunidad probatoria. 
se inserta en esta categoría, puesto que la resolución que pone fin al recurso (generalmente en el sentido de confirmar, modificar o dejar sin efectos el acto administrativo recurrido) es "preparada" por la autoridad, brindando al recurrente, por ejemplo, la posibilidad de subsanar o corregir deficiencias mediante la notificación de prevenciones, así como de ofrecer y exhibir pruebas adicionales.

En este orden de ideas, el recurso que nos ocupa participa de la naturaleza de los "procedimientos seguidos en forma de juicio", en los cuales las autoridades están obligadas a privilegiar la solución del conflicto sobre los formalismos procedimentales. Así lo consideró, por ejemplo, el Pleno de la SCJN en la tesis jurisprudencial P./J. 25/96, ${ }^{39}$ donde estableció que el recurso está sujeto a los principios fundamentales que norman el debido proceso legal $\mathrm{y}$, en particular, a las garantías consagradas en el artículo 14 de la CPEUM, para no dejar al particular recurrente en estado de indefensión.

En virtud de esta naturaleza, en el recurso de revocación impera el principio pro actione y está proscrito el ritualismo.

\section{Aplicación de la doctrina del exceso ritual manifiesto al recurso}

Con lo expuesto hasta este punto, es evidente que en el recurso administrativo confluye la doctrina del exceso ritual manifiesto con la del recurso judicial efectivo, sustentada por en la jurisprudencia interamericana. En el Caso Ivcher Bronstein vs. Perú, la Corte IDH sostuvo que todos los órganos que ejerzan funciones materialmente jurisdiccionales deben adoptar sus decisiones respetando el debido proceso. ${ }^{40}$ La propia Corte IDH argumentó, en el Caso Paniagua Morales y otros, que el elenco de garantías para el debido proceso legal se aplica también al orden administrativo y fiscal. ${ }^{41}$ Entre estas garantías, de acuerdo con el artículo 8 , numerales 1 y 2, y 25, de la Convención Americana sobre Derechos Humanos, se encuentran la de ser oído en juicio efectivo y no formalista.

Por consiguiente, el estándar interpretativo conocido como principio pro actione, estrechamente relacionado con el principio pro homine, no es exclusivo de la materia penal, ni de los procesos judiciales. El recurso de revocación conforma, junto con el juicio contencioso administrativo, un sistema de medios de defensa que permiten impugnar las resoluciones de las autoridades fiscales, en sede administrativa o en sede jurisdiccional, respectivamente..$^{42}$ De allí que ambos

Así lo sostuvo, por ejemplo, el Tercer Tribunal Colegiado en Materia Administrativa del Primer Circuito (1989) en la tesis aislada de rubro "PROCEDIMIENTOS ADMINISTRATIVOS SEGUIDOS EN FORMA DE JUICIO”. Consultable en: Semanario Judicial de la Federación, Octava Época, t. III, Segunda Parte-2, enerojunio de 1989, p. 579.

39 Tesis P./J. 25/96, Semanario Judicial de la Federación y su Gaceta, Novena Época, t. III, junio de 1996, p. 96.

40 Corte IDH, Caso Ivcher Bronstein vs. Perú, fondo, reparaciones y costas, sentencia de 6 de febrero de 2001, serie C, núm. 74.

41 Corte IDH, Caso Paniagua Morales y otros, sentencia de 8 de marzo de 1998. Serie C No. 37.

42 Como lo expresó el Primer Tribunal Colegiado en Materia Administrativa del Sexto Circuito en la tesis VI.1o.A. J/3 (10a.) Consultable en: Semanario Judicial de la Federación y su Gaceta, décima época, libro XV, diciembre de 2012, t. 2, p. 1116. 
medios — recurso y juicio — deban cumplir con los requisitos de accesibilidad y efectividad.

En consonancia con lo anterior, los motivos legislativos para crear un medio de defensa particularmente sencillo, con pocas formalidades, que pueda ser utilizado por personas poco versadas en la materia fiscal, sirven como respaldo para el principio especial de informalismo que distingue al recurso de revocación. Es decir, por tratarse de un recurso concebido con una especial aversión al ritualismo, la imposición de formalidades en el recurso de revocación merece un escrutinio más riguroso que en los procesos jurisdiccionales. ${ }^{43}$

Cabe concluir que en el recurso existe una mayor probabilidad de que el uso de las formas resulte desproporcionado, irrazonable o abusivo, tomando en cuenta que el legislador lo diseñó con la intención de que resultara especialmente rápido y sencillo, con un estándar de formalidades mínimas. Máxime si en el recurso administrativo no existe una contienda de partes cuya igualdad se deba preservar, lo cual descarta el riesgo de violar el principio de imparcialidad en caso de exceptuar al recurrente de un formalismo.

\section{Razonabilidad y excesos de los formalismos en el recurso}

El exceso ritual manifiesto solo es identificable por medio de análisis casuísticos, toda vez que sigue una regla de excepcionalidad y responde a las circunstancias especiales del caso. En este sentido, Bertolino cita la opinión de la Corte Suprema de Justicia de Santa Fe, Argentina, sobre la dificultad de distinguir entre la formalidad razonable y el formalismo exacerbado: "la calificación de un acto jurisdiccional como afectado de exceso ritual requiere cautela y prudencia especiales y fino sentido jurídico capaz de detectar el empleo razonable e irrazonable de las normas de procedimiento". ${ }^{44}$

Como se ha visto, el informalismo del recurso debería inspirar en las autoridades resolutoras especial prudencia con las formalidades; no porque el recurso se deba desenvolver improvisamente, sino en virtud de la exigencia de vigilar que dichas formas sean mínimas, las estrictamente indispensables para preservar la seguridad jurídica.

Luego, el recurso de revocación es un escenario idóneo para que las autoridades apliquen la doctrina del exceso ritual, especialmente en su vertiente de

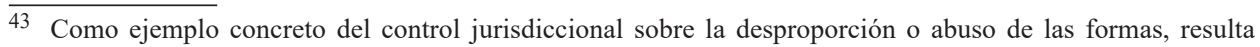
interesante la tesis XVI.1o.A.113 A (10a.), sustentada por el Primer Tribunal Colegiado en Materia Administrativa del Décimo Sexto Circuito, con el título: "RECURSO DE REVOCACIÓN. LA REGLA 2.18.1 DEL ANEXO 1-A DE LA RESOLUCIÓN MISCELÁNEA FISCAL PARA 2014, AL EXIGIR QUE ESE MEDIO DE DEFENSA SE PRESENTE DESDE EL LUGAR EN QUE RESIDE EL RECURRENTE, VIOLA EL DERECHO A UN RECURSO EFECTIVO Y, POR TANTO, DEBE DESAPLICARSE." A partir de la interpretación relacionada de los artículos 17 Constitucional y 25 de la Convención Americana sobre Derechos Humanos, el tribunal encontró que la regla en cuestión "limita irracionalmente el acceso a un recurso efectivo", ya que, si mediante el buzón tributario el recurso puede enviarse desde cualquier parte del mundo, no existe justificación para que cuando, excepcionalmente, el recurso se pueda plantear mediante un escrito impreso y se use el correo postal, se tenga que depositar desde el lugar donde esté el domicilio del contribuyente.

BerTOlino, Pedro, op. cit., p. 67. 
atenuación de las reglas procedimentales en casos excepcionales. Es así, porque dicha figura no requiere - como sí pueden hacerlo los principios de interdicción de la arbitrariedad y pro actione - un pronunciamiento sobre la regla en sí misma, en el sentido de ponderar si se adecua a diversos principios constitucionales y, de no ser así, desaplicarla en cualquier caso.

Para ilustrar esta postura, enseguida se describen algunos escenarios donde la aplicación rígida y mecánica de las disposiciones formales resultaría en la tramitación de un recurso con un fin meramente formalista.

a) Tener por no interpuesto el recurso sin apercibimiento previo, por el solo hecho de no señalar una dirección de correo electrónico en el cuerpo del escrito.

El artículo 122 del CFF enuncia los requisitos especiales del escrito de interposición del recurso de revocación, al tiempo que recalca la aplicabilidad de los requisitos generales de la promoción en materia fiscal. Estos últimos requisitos son los previstos en el artículo 18 del mismo ordenamiento. Para el caso de las promociones electrónicas es obligatorio señalar el nombre, la denominación o razón social del promovente; el domicilio fiscal manifestado al Registro Federal de Contribuyentes (RFC) y la clave que corresponde a dicho registro; la autoridad a la que se dirige y el propósito de la promoción, así como una dirección de correo electrónico para recibir notificaciones.

El párrafo subsecuente del artículo 18 establece un régimen de prevenciones para el caso de que no se cumplan los requisitos ya señalados, otorgando al promovente la oportunidad de corregir sus errores o subsanar sus omisiones. Sin embargo, en forma irrazonable y desproporcionada, el mismo párrafo agrega un segundo supuesto en el cual se puede tener por no presentado el escrito: cuando se omita señalar la dirección de correo electrónico.

Es decir, la mera falta de señalamiento de la dirección de correo electrónico conducirá a la desestimación de la promoción, sin mediar prevención. Esa consecuencia normalmente vendrá aparejada a la pérdida de toda oportunidad para impugnar los actos lesivos; puesto que el plazo dentro del cual se pueden impugnar éstos generalmente se habrá extinguido para cuando el interesado se entere de que su promoción se tuvo por no presentada.

Es de por sí cuestionable la constitucionalidad de la norma que restringe la posibilidad de subsanar una cuestión formal, como lo es el señalamiento de un correo electrónico. Más allá de ello, en el recurso de revocación se traduce en ritualismo, derivado de la exigencia irreflexiva de requisitos formales que no sirven otro propósito más que impedir el pronunciamiento de fondo. Ello, porque las autoridades hacendarias cuentan, casi siempre, con los datos necesarios para identificar al recurrente y el lugar o los medios por los cuales pueda practicar las notificaciones necesarias para llevar a término el procedimiento.

Dicha exigencia es especialmente innecesaria en el caso de los recursos enviados por medio del buzón tributario. De acuerdo con el artículo 17-K del CFF, 
cada persona inscrita en el RFC tendrá asignado un buzón tributario. En este entendido, el buzón está asociado a una sola clave del RFC; por lo tanto, bastaría con la indicación de la clave, o de cualquier dato que permita a la autoridad identificarla, para que ésta pueda enviar las notificaciones necesarias a dicho buzón. En vista de que las notificaciones se practican, en realidad, en el buzón tributario y no por correo electrónico, ¿qué sentido tiene exigir la dirección de éste en todo escrito de interposición? ¿Qué justificación se encuentra para que su falta no amerite una oportunidad para subsanarla?

La formalidad en cuestión es menos importante que el resto de los requisitos mencionados en el artículo 18 del CFF; sin embargo, es el único requisito que no se permite subsanar. En este orden de ideas, el no obviar la falta de señalamiento de la dirección de correo electrónico en el escrito de interposición; ni dar al promovente, cuando menos, la oportunidad para subsanar su falta, representa un exceso ritual manifiesto.

b) Tener el recurso por no interpuesto, en virtud de la carencia de identificación oficial vigente del promovente.

En forma similar a los requisitos propios del artículo 18 del CFF, el numeral 122 también señala que, cuando el recurso no se interponga en nombre propio, la representación deberá acreditarse en términos del artículo 19 del mismo código. En el aludido artículo 19 se encuentra la prohibición — razonable — de la gestión de negocios en materia fiscal, así como los requisitos generales para comprobar las facultades de representación.

Sin embargo, en la misma disposición se exige complementar la prueba de la personalidad con la copia de la identificación del contribuyente o representante legal, previo cotejo con su original. Esta última exigencia da pie a diversas posturas ritualistas, cuando se trata de ventilar un recurso administrativo y no un trámite fiscal genérico.

Por destacar un supuesto, es fácil imaginar el caso de que una persona se encuentre ante la urgencia de interponer un recurso - sea por la proximidad del vencimiento del plazo para promoverlo o por el deseo de obtener la suspensión de la ejecución- y se percate de que no cuenta con identificaciones vigentes, por habérsele extraviado, dañado o caducado su vigencia. Aunque la omisión de dichos documentos es subsanable a requerimiento de la autoridad — para lo cual se otorga al particular un plazo de cinco días hábiles - dicha prevención sirve de poco a quien necesita más tiempo para otras instituciones le expidan o repongan sus identificaciones; o bien, al interesado que momentáneamente no cumpla los requisitos para obtener estas últimas. En cambio, la consecuencia de no satisfacer la prevención es de gran magnitud, puesto que se tendría por no interpuesto el recurso.

Lo anterior a pesar de que la identificación no es, por lo general, un documento que acredite la existencia de la acción. Por eso, la exigencia irreflexiva de aportar copia cotejada de la identificación oficial es un exceso ritual que se opone a la vigencia de derechos. 
En el caso de los recursos electrónicos, lo irrazonable de este formalismo radica en que el envío se realiza dentro de un sistema hermético, para acceder al cual es indispensable una contraseña personal. Asimismo, es necesario utilizar una firma electrónica (e.firma) respaldada con un certificado. La obtención del certificado implica, entre otras cosas, que el interesado se presente en las oficinas de la autoridad y se identifique con documentos idóneos para que se le tomen datos biométricos, incluyendo sus huellas digitales y fotografía del iris. Esa firma digital no es repudiable para fines administrativos: el titular no puede desconocerla, argumentando que alguien más tuvo acceso a sus archivos y contraseñas. Cuando se trata de personas morales, el artículo 19-A del CFF autoriza a presumir, sin que se admita prueba en contrario, que los documentos digitales que contengan su firma electrónica fueron presentados por el administrador único o por cualquier otro representante idóneo, independientemente de la denominación de su cargo.

En esta virtud, el uso de la firma electrónica identifica plenamente a quien obtuvo el certificado que la respalda y, en todo caso, el SAT cuenta con un expediente de datos biométricos y documentales que asocian cada firma a una persona en particular. Así, por las particularidades del recurso de revocación y lo robusto del padrón - RFC - que administra la autoridad, anexar una identificación cotejada es menos relevante para preservar la seguridad jurídica que en otra clase de procedimiento.

En contraste, en los juicios contenciosos administrativos y los de amparo, los órganos jurisdiccionales observan el principio de buena fe y únicamente cuestionarán la identidad de quien suscribió las promociones cuando existan indicios de falsedad o suplantación; sin necesidad de contar con documentos de identificación en todos los casos. Esto conlleva que el recurso aparente ser más formalista que otros medios de defensa disponibles contra los mismos actos, cuando debería ser lo opuesto.

c) Tener el recurso por no interpuesto, sin mediar apercibimiento o prevención, cuando el recurso se presente por medios tradicionales en lugar de electrónicos.

Ya se ha mencionado que la legislación vigente impone como obligación, y no como opción, la interposición del recurso por medios electrónicos, concretamente el buzón tributario. ${ }^{45}$ Así pues, en principio, los recurrentes no tienen la opción de formular un escrito de interposición en medios impresos; tampoco pueden enviarlo por medio del servicio postal, ni presentarlo directamente en las oficialías de partes de las unidades administrativas competentes.

45 Como excepción, la regla 2.17.1 de la Resolución Miscelánea Fiscal para 2021 y la ficha de trámite 192/CFF de su Anexo 1-A, señalan que las promociones formuladas por quienes no se encuentren obligados a inscribirse en el RFC o a tramitar la "e.firma", al igual que las que se presenten ante las autoridades de las entidades federativas, se realizarán mediante escrito en papel. A esos supuestos debemos añadir los recursos de revocación dirigidos a autoridades fiscales distintas del SAT, que no hayan implementado el uso obligatorio del buzón tributario. 
Ahora bien, el artículo 133, fracción I, del CFF establece que la resolución definitiva del recurso de revocación puede desecharlo por improcedente, tenerlo por no interpuesto o sobreseerlo. ${ }^{46}$ Sin embargo, ninguno de los artículos del CFF expresa cuál es la consecuencia de presentar un recurso de revocación por medios tradicionales, en lugar de hacerlo a través del buzón tributario. Incluso, entre las causales de improcedencia que contempla el artículo 124 no se encuentra la de haberse presentado el recurso mediante un escrito impreso. Así pues, la sola previsión de que el recurso deberá presentarse electrónicamente no tiene implícita la autorización a las autoridades para desechar o tener por no interpuestos los recursos cuando no se emplee este medio.

En todo caso, resulta que la interposición tradicional, cuando debía ser electrónica, no es más que una cuestión formal, fácilmente subsanable. En esa medida, podría y debería ser materia de requerimiento para que la recurrente, dentro del plazo de cinco días hábiles, presente su recurso a través del sistema electrónico.

Si los elementos sustanciales y de procedibilidad están satisfechos, la interposición en forma impresa no impide entablar la relación jurídica propia del medio de defensa. Existiendo certeza de la voluntad de una persona para impugnar un acto (evidenciada con un escrito firmado que contenga agravios); la precisión del acto impugnado y la prueba de su existencia, así como de la oportunidad de la interposición, no hay obstáculo razonable para el trámite del recurso. Lo anterior, desde luego, a reserva de que se compruebe una causal distinta de improcedencia o sobreseimiento. Las autoridades deben dar prioridad al hecho de que se encuentren satisfechos los requisitos esenciales del recurso.

Asimismo, la interposición por medios impresos no entorpece el trámite del recurso ni otorga ventajas indebidas al recurrente, siempre y cuando se presente dentro del plazo legal, directamente ante la autoridad competente para resolverlo, o bien, ante aquella que haya emitido el acto recurrido.

Se reitera que la implementación del recurso en línea no se orientó a satisfacer aspectos sustantivos de la relación jurídico-tributaria ni a modificar los requisitos esenciales del medio de defensa; sino, exclusivamente, a simplificar y agilizar la tramitación del recurso ya previsto en la ley.

De tal suerte que el requisito de interposición electrónica únicamente repercute en el formato o continente de la pretensión. En uno y otro caso (por medios impresos o electrónicos) se genera un documento, radicando la diferencia simplemente en que los datos estén expresados mediante letras impresas en papel, o bien, mediante dígitos que conforman un documento electrónico. La diferencia en el

\footnotetext{
46 La consecuencia de tener el recurso por no interpuesto cabe cuando no se anexen al escrito respectivo - previo requerimiento de la autoridad - los documentos que acrediten su personalidad y aquellos que contengan el acto impugnado o la constancia de su notificación, cuando quepa. El desechamiento, en cambio, es factible cuando no se expresen agravios en el escrito de interposición, a pesar de haberse formulado requerimiento para expresarlos, pues así se desprende del artículo 122, último párrafo, del CFF. Esta consecuencia también es aplicable cuando exista, al momento de la interposición, alguna de las causales de improcedencia previstas en el artículo 124 del mismo ordenamiento.
} 
medio de expresión no es trascendente ni insalvable, tanto así que los documentos impresos pueden digitalizarse y los electrónicos pueden imprimirse.

No hay razón, pues, para asumir que la exhibición del escrito por un medio distinto al buzón tributario sea una irregularidad de mayor trascendencia que, por ejemplo, la falta de agravios o la indicación del acto impugnado, las cuales no conducen al desechamiento del plano (o sin previo requerimiento) del recurso.

Por otro lado, el artículo 18 del CFF dispone que, cuando no se cumplan los requisitos establecidos para los escritos libres, las autoridades fiscales requerirán al promovente a fin de que cumpla con el requisito omitido y, si la omisión consiste en no haber usado la forma oficial aprobada, las autoridades fiscales deberán especificar en el requerimiento la forma respectiva. Las autoridades pueden aplicar esta última previsión al recurso de revocación mediante una interpretación extensiva y pro homine, dado que el buzón tributario, en realidad, contiene un asistente o formulario electrónico, dividido en diversas páginas o apartados que el contribuyente debe ir llenando en el orden requerido para avanzar hasta su parte final, donde se le permite firmar la promoción electrónicamente.

En otras palabras, existe una suerte de "forma electrónica oficial" para enviar el medio de defensa y, si la autoridad imputa al recurrente la omisión de utilizarla, lo correcto es que le prevenga para que formule su pretensión por ese medio, especificando que debe hacerlo mediante el módulo aplicable del buzón tributario.

Así pues, cuando las autoridades desechan o tienen por no interpuestos los recursos presentados en medios tradicionales, incurren en exceso ritual por aplicación de disposiciones que se oponen a la vigencia de derechos. Es así, porque extienden indebidamente la aplicación de las figuras interruptoras de la jurisdicción, al tiempo que dejan de observar las normas que les autorizan a formular una prevención para que el promovente subsane la irregularidad utilizando el buzón tributario.

No obstante, hasta la fecha se suscitan casos en los cuales se tiene por no interpuesto el recurso de revocación por la sola razón de no haberlo hecho llegar a la autoridad por un canal específico. Un ejemplo reciente y significativo es el del juicio Contencioso Administrativo número 1534/17-EC1-01-6/2170/18S1-02-04, resuelto por la Primera Sección de la Sala Superior del Tribunal Federal de Justicia Administrativa ${ }^{47}$. Allí, la Sala administrativa determinó "si la única vía de presentación del recurso es a través de buzón tributario, la consecuencia jurídica de no hacerlo así, (sic) es que se tenga por no presentado", confiriendo mayor importancia a la "vía" — en realidad, el medio de comunicación-que a la relación jurídica administrativa subyacente, y a la resolución del conflicto de fondo. Como justificación esencial para su decisión, la Sala se limitó a argumentar que el derecho de acceso a la justicia no es irrestricto, puesto que está condicionado a "seguir los formalismos" que señale el legislador para ejercerlo. En otras palabras, vemos nuevamente elevados los formalismos a la categoría de fines.

47 Precedente VIII-P-1aS-766, Revista del Tribunal Federal de Justicia Administrativa, octava época, año V, núm. 49, diciembre 2020, p. 294. 


\section{Caso Herrera}

Por su utilidad para contrastar estas últimas premisas, vale la pena hacer referencia al fallo dictado por la Suprema Corte de Justicia de la Provincia de Buenos Aires el 3 de octubre de 2018. ${ }^{48}$ En síntesis, el caso versó sobre la apelación de una sentencia dictada en un proceso tramitado durante las primeras épocas de implementación de un nuevo sistema de presentaciones y notificaciones electrónicas. ${ }^{49}$ La Cámara de Apelaciones tuvo a los apelantes por no señalando domicilio electrónico y, por ende, les tuvo por constituido el domicilio en los estrados del tribunal. Por este último medio se notificó el requerimiento para expresar agravios y, no habiéndolo atendido los apelantes, se declaró desierto el recurso.

La Corte, por su parte, reconoció el carácter obligatorio del sistema de notificaciones electrónicas y que la Cámara, en sentido estricto, se apegó a las normas vigentes al momento de producirse los actos procesales. No obstante, aquella valoró los antecedentes del caso y concluyó que, por la manera como se ventilaron las instancias previas, resultaba esperable para los apelantes que el requerimiento para expresar agravios se notificara por medios tradicionales (cédula en papel) en su domicilio físico, o bien, que se les previniera para constituir domicilio electrónico antes de tenerles por señalados los estrados del Tribunal. Ello porque en todo el trámite de la primera instancia ninguna de las partes cumplió con la carga de señalar un domicilio procesal electrónico, y todas las notificaciones se les formularon en domicilio físico y en formato papel; a pesar de tratarse de notificaciones que —en principio - debían practicarse por la vía electrónica. Fue así, porque, después de la entrada en vigor de las normas relativas a la esta última, diversos acuerdos y resoluciones fueron graduando y prorrogando su aplicación obligatoria.

Postuló la Suprema Corte bonaerense que no fue reprobable el haber tenido por constituido el domicilio en los estrados del tribunal; ${ }^{50}$ sino que el apercibimiento formulado mediante estrados resultara sorpresivo y gravosamente desproporcionado para la parte recurrente, en el contexto de tramitación en el que venía desarrollándose el expediente.

De dicho contexto, la Corte resaltó que existieron aplicaciones disímiles para una misma reglamentación que fue objeto de sucesivas modificaciones y aclaraciones, además de recaer sobre una materia novedosa. En respuesta a esas circunstancias, la Cámara de apelaciones debía adoptar una interpretación flexible y contextualizada, guiada por un criterio de razonabilidad, que evite encerronas o sorpresas procesales para los justiciables, pues ese no ha sido el espíritu que inspiró el dictado de dichas normas. Mediante esa interpretación, era necesario hacer una prevención por medios tradicionales a los apelantes.

\footnotetext{
48 Suprema Corte de Justicia de la Provincia de Buenos Aires, causa C 121.320, Herrera, Ricardo Horacio y otro/a contra Herrera, María Aurora. Desalojo, fallo del 3 de octubre de 2018.

49 QUADRI, Gabriel H., "Lo electrónico y el exceso ritual (unas breves reflexiones a mano alzada, a propósito de 'Herrera')", E-Procesal - Foro de Derecho Procesal Electrónico, 15 de octubre de 2018, http://e-procesal. com/lo-electronico-y-el-exceso-ritual-unas-breves-reflexiones-a-mano-alzada-a-proposito-de-herrera-1852 QUADRI, Gabriel H., op. cit.
} 
Así pues, el Caso Herrera es un ejemplo de la aplicación de la doctrina del exceso ritual en los procesos sujetos a innovaciones tecnológicas. La presencia de éstas debe conducir a una flexibilidad mayor, contextualizada por los antecedentes del caso y la aplicación desigual o errática que normalmente traen aparejada en sus primeras etapas de funcionamiento. Como lo expresa Quadri, ${ }^{51}$ el fantasma del exceso ritual se potencia con la llegada nuevas tecnologías. Algunas cuestiones — señala el mismo autor - son ajenas a los usuarios, tales como las consecuencias desproporcionadas que contemple la normativa, los problemas técnicos y los propios del diseño estructural del sistema; otras tantas derivan de la conducta poco diligente de los usuarios, sean justiciables u operadores jurídicos; mientras que el resto se sitúan en áreas grises o de combinación de elementos.

\section{Caso Sánchez Rodolfo Horacio y otros}

En otro caso reciente, el 5 de abril de 2020, la Cámara Segunda Civil y Comercial (Sala I) de La Plata también falló sobre la existencia de ritualismo, cometido al declararse desierto un recurso en la primera instancia de un proceso civil, por haberse enviado equivocadamente el escrito de agravios a través del sistema electrónico de la instancia de origen, en lugar del administrado por el órgano de alzada. ${ }^{52}$

La sentencia definitiva va más allá de la abstracción del concepto “expediente" y reconoce que las particularidades de un sistema donde existe un expediente digital para la primera instancia y uno diverso para lo actuado ante la Cámara en segunda instancia genera confusiones. Invocando la doctrina del exceso ritual manifiesto, el órgano jurisdiccional estimó que el error incurrido al "cliquear" el envío del archivo electrónico constituye un error de hecho excusable. Concluyó el tribunal de alzada que la irregularidad formal del acto procesal no afectaba su validez, atendiendo a dos consideraciones principales: que el acto logró alcanzar la finalidad a la cual estaba destinado y no causó perjuicio ni conculcación de derechos a la contraparte. ${ }^{53}$

Los dos casos examinados en la jurisprudencia argentina abonan a la perspectiva de que, en el caso de los recursos de revocación que, debiendo sustanciarse en línea conforme al CFF, se presenten en forma impresa, es dable valorar si se trató de una conducta negligente del justiciable y si la magnitud de la consecuencia - desechar o tener por no interpuesto el recurso - resulta desproporcionada en el caso particular. Lo anterior es inherente a la interpretación flexible y

51 Idem.

52 Se expone en la sentencia de la Cámara: "Si bien dicha presentación fue correctamente dirigida a esta Alzada y efectuada dentro del plazo previsto por el artículo 254 del CPCC (ver referencias de fs. 427 vta. e informe y despacho de fs. 430), medió equivocación respecto a la dependencia en la cual aquella debió ser hecha ya que quedó registrada en el sistema informático de la instancia de origen, donde había tramitado la causa, en vez de hacerlo en la Cámara."

53 Cfr. Cámara Segunda Civil y Comercial (Sala I) de La Plata, causa 126956, Sánchez Rodolfo Horacio y Otros c/ Acosta Alberto Alfredo y Otro/ A S/ Daños y Perj. Autom. c/Les. o Muerte (Exc.Estado), fallo del 12 de marzo de 2020. 
contextualizada que siempre debe hacerse sobre las formas, existan o no componentes tecnológicos.

\section{Reflexión final}

La doctrina del exceso ritual manifiesto y el amplio bagaje de jurisprudencia internacional que la soporta, han cobrado mayor relevancia en México a raíz de la reforma al artículo 17 Constitucional, al cual se incorporó un mandato expreso de dar prioridad al derecho sustancial por sobre el procedimental.

Antes de dicha reforma, los tribunales de nuestro país ya aplicaban diversas técnicas judiciales no formalistas con el fin de proscribir el ritualismo. Entre ellas, destaca la aplicación del principio pro actione, que autoriza a los juzgadores a decidir contra el tenor literal de una norma en casos especiales y encontrar flexibilidades razonables, en aras de favorecer la acción y resolver el fondo de los asuntos.

Al margen de la aplicación de doctrinas con diferentes orígenes y alcances, privilegiar la solución del conflicto sobre los formalismos es una tarea jurisdiccional especialmente complicada, comenzando por distinguir las cargas razonables de las irrazonables. La descalificación de los formalismos, explica Carrióo, ${ }^{54}$ debe estar sustentada en buenas razones; puesto que la doctrina que proscribe el abuso de las formas no tiene por qué causar una mayor inseguridad jurídica mayor a la originada por la aplicación rígida de la ley. La jurisprudencia interamericana y el derecho comparado sirven como brújulas En esta delicada labor, por su experiencia en la tutela de la prevalencia de la norma sustancial.

No escapan a dichos alcances los procedimientos seguidos en forma de juicio, a los cuales también les aplica el mandato de prevalencia del derecho sustancial. En esta categoría se encuentra el recurso de revocación fiscal. Luego, las autoridades encargadas de resolver los recursos están obligadas a realizar una interpretación flexible y contextualizada de las normas, guiada por un criterio de razonabilidad. Tal flexibilidad, de hecho, debería manifestarse con mayor naturalidad en el recurso de revocación, toda vez que el legislador lo creó con la intención de reducir formalismos, preservando únicamente las formalidades indispensables para mantener la seguridad jurídica. La posterior adecuación al recurso, relativa a su sustanciación electrónica, es afín a esos motivos legislativos y debe interpretarse en armonía con ellos.

Sin embargo, en los hechos, los recursos administrativos como el de revocación son más propensos a las interpretaciones rigoristas y a la aplicación mecánica de las formas. La razón es que el conductor del recurso no es un juez, sino una autoridad administrativa; más inclinada, por sus funciones y su formación, a la aplicación literal de las normas, aunado a que no está sujeta a las técnicas jurisdiccionales no formalistas ni a la jurisprudencia sobre la materia.

Encontramos, pues, una paradoja en el recurso de revocación. Aunque su regulación abstracta es ligera en cuanto a las formas, presenta formalidades de

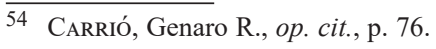


dudosa utilidad y con alto riesgo de aplicación rigorista, de las cuales se estudiaron algunos ejemplos en este trabajo. En tales aspectos, el recurso parece ser más ritualista que los juicios aplicables al mismo género de actos, como el de nulidad o el amparo indirecto.

No deja de ser importante que el recurso de revocación se conduzca en forma ordenada y previsible, aplicando con seriedad las normas del CFF relativas a la admisibilidad del escrito, la legitimación y personalidad, la oportunidad en la interposición, la competencia del órgano al cual se dirija, o los documentos de los cuales depende la pretensión. La doctrina del exceso ritual manifiesto no debería conducir a admitir recursos en contra de actos no impugnables ni a ampliar el plazo de interposición, entre otros supuestos.

En cambio, toda regla adjetiva que impida u obstaculice el pronunciamiento sobre el fondo de la controversia, sin abonar significativamente a la seguridad jurídica, debe interpretarse con amplitud de criterio, atendiendo al contexto, y, de ser necesario, exceptuar o dar una oportunidad adicional para su cumplimiento. Actuando de esa manera, las autoridades harían efectiva la vocación del recurso de revocación como medio sumario, económico e informal para resolver controversias fiscales.

\section{Bibliografía}

\section{Fuentes consultadas}

Armienta Hernández, Gonzalo, Tratado Teórico Practico De Los Recursos Administrativos, 9a. ed., México, Porrúa, 2013.

Badillo García, Armando A., "El juicio de amparo y sus formalismos procedimentales: Algunas notas sobre el papel de los jueces de distrito", Revista del Instituto de la Judicatura Federal, núm. 45, enero-junio, México, 2018, https://www.ijf.cjf.gob.mx/Sitio2016/include/sections/revista/45/2_Armando\%20Antonio $\% 20$ Badillo\%20Garc\%C3\%ADa_.pdf

Bertolino, Pedro, El exceso ritual manifiesto, 2a. ed., La Plata, Librería Editora Platense, 2003.

Caicedo Villamizar, Alexander E. "El exceso ritual manifiesto y la visión constitucional de la actividad judicial", Justicia, núm. 32, 79-117, julio-diciembre, España, Barranquilla, 2017, https://doi.org/10.17081/just.23.32.2907

CARrió, Genaro R., "Exceso ritual manifiesto y garantía constitucional de la defensa en juicio", Revista del Centro de Estudios Constitucionales, núm. 7, 57-77, julio-diciembre, España, 2018, https:/dialnet.unirioja.es/descarga/ articulo/1050537.pdf

Castillo Sotomayor, Guillermo, “Actos materialmente administrativos: Su complementación en el juicio de Amparo indirecto para una justicia Constitucional integral" Revista del Instituto de la Judicatura Federal, núm. 45, 299267, enero-junio, México, 2018, https://www.ijf.cjf.gob.mx/Sitio2016/ include/sections/revista/45/12_Guillermo\%20Castillo\%20Sotomayor.pdf 
Camps, Carlos E. (Coord.), 2021, Cuadernos de doctrina legal número V - Derecho Procesal Electrónico, La Plata, Suprema Corte de Justicia de la Provincia de Buenos Aires, https:/www.scba.gov.ar/jurisprudencia/14\%20-\%20 Derecho\%20Procesal\%20Electr\%C3\%B3nico.pdf

Flores Ayvar, Lawrence, "El exceso ritual manifiesto", en Godínez Méndez, Wendy y García Peña, José H. (coords.), Temas actuales del derecho. El derecho en la globalización, México, 2014, Instituto de Investigaciones Jurídicas, https://archivos.juridicas.unam.mx/www/bjv/libros/8/3826/14.pdf

García, Pedro A. y Acevedo Prada, Milena, La doctrina de la corte constitucional colombiana sobre el exceso ritual manifiesto en materia de pruebas, Vniversitas, Bogotá, núm. 127, julio-diciembre 2013, 127-156, https://doi. org/10.1144/Javeriana.VJ127.decc

Gozaíni, Osvaldo, A., "Funciones del juez en los procesos Constitucionales", Estudios Constitucionales, año 4, núm. 1, 299-332, México, Instituto de Investigaciones Jurídicas UNAM, https://www.redalyc.org/articulo.oa?id $=82040217$

PAz, Alejando, El Recurso de Revocación en Materia Fiscal, 4a. ed., México, Ediciones Fiscales ISEF, 2017.

Orellana Wiarco, Octavio A. Derecho Procesal Fiscal, 4a. ed., México, Porrúa. SERrano Hoyo, Gregorio, "Formalismo y tutela judicial efectiva en la jurisprudencia del Tribunal Constitucional", Anuario de la Facultad de Derecho, núm. 10, 119-168, 1992, España, Universidad de Extremadura, https://dialnet.unirioja.es/servlet/articulo?codigo $=119296$

QuADRI, Gabriel H., "Lo electrónico y el exceso ritual (unas breves reflexiones a mano alzada, a propósito de 'Herrera')", E-Procesal, Foro de Derecho Procesal Electrónico, 15 de octubre de 2018, http://e-procesal.com/lo-electronico-y-el-exceso-ritual-unas-breves-reflexiones-a-mano-alzada-a-propositode-herrera-1852

\section{Jurisprudencia nacional}

Pleno de la Suprema Corte de Justicia de la Nación, P./J. 25/96, Semanario Judicial de la Federación y su Gaceta, Novena Época, t. III, junio de 1996, p. 96.

Primera Sala de la Suprema Corte de Justicia de la Nación, 1a./J. 58/2019, Semanario Judicial de la Federación, Décima Época, Libro 48, viernes 11 de octubre de 2019 10:21 h.

Primera Sala de la Suprema Corte de Justicia de la Nación, 1a./J. 90/2017, Gaceta del Semanario Judicial de la Federación, Décima Época, Libro 48, noviembre de 2017, t. I, p. 213.

Primera Sala de la Suprema Corte de Justicia de la Nación, 1a./J. 42/2007, Semanario Judicial de la Federación y su Gaceta, Novena Época, t. XXV, abril de 2007, p. 124. 
Primera Sección de la Sala Superior del Tribunal Federal de Justicia Administrativa, VIII-P-1aS-766, Revista del Tribunal Federal de Justicia Administrativa, Octava Época, año V, núm. 49, diciembre 2020, p. 294.

Primer Tribunal Colegiado en Materia Administrativa del Décimo Sexto Circuito, XVI.1o.A.113 A (10a.), Gaceta del Semanario Judicial de la Federación, Décima Época, Libro 35, octubre de 2016, t. IV, p. 3080.

Primer Tribunal Colegiado en Materia Administrativa del Sexto Circuito, VI.1o.A. J/3 (10a.), Semanario Judicial de la Federación y su Gaceta, Décima Época, Libro XV, diciembre de 2012, t. 2, p. 1116.

Segunda Sala de la Suprema Corte de Justicia de la Nación, 2a./J. 22/2003, Semanario Judicial de la Federación y su Gaceta, Novena Época, t. XVII, abril de 2003, p. 196.

Tercer Tribunal Colegiado en Materia Administrativa del Primer Circuito, Semanario Judicial de la Federación, Octava Época, t. III, Segunda Parte-2, enero-junio de 1989, p. 579.

\section{Jurisprudencia internacional}

Corte IDH, Caso del Tribunal Constitucional, sentencia de 31 de enero de 2001. Serie C No. 71.

Corte IDH, Caso Ivcher Bronstein vs. Perú, fondo, reparaciones y costas, sentencia de 6 de febrero de 2001, serie C, núm. 74.

Corte IDH, Caso Paniagua Morales y otros, sentencia de 8 de marzo de 1998. Serie C No. 37.

Corte IDH, Caso Trabajadores Cesados del Congreso (Aguado Alfaro y otros) VS. Perú, sentencia de 24 de noviembre de 2006. Serie C No. 158.

Cámara Segunda Civil y Comercial (Sala I) de La Plata, causa 126956, Sánchez Rodolfo Horacio y Otros c/ Acosta Alberto Alfredo y Otro/ A S/ Daños y Perj. Autom. c/Les. o Muerte (Exc.Estado), fallo del 12 de marzo de 2020. Corte Suprema de Justicia de la Nación Argentina, Colalillo, Domingo c/ Compañía de Seguros España y Río de la Plata, fallos 238:550; LL 89-412; JA 1957-IV-477, fallo del 18 de setiembre de 1957.

Suprema Corte de Justicia de la Provincia de Buenos Aires, causa C 120678, Edificio Alem 1659/1667 U.F. s/ Incidente de Venta en Constructora Berutti S.A. Quiebra, fallo del 29 de enero de 2018.

Suprema Corte de Justicia de la Provincia de Buenos Aires, causa C 121.320, Herrera, Ricardo Horacio y otro/a contra Herrera, María Aurora. Desalojo, fallo del 3 de octubre de 2018.

\section{Legislación nacional}

Código Fiscal de la Federación.

Constitución Política de los Estados Unidos Mexicanos.

Gaceta del Senado, LX/3PPO-277/18329, 21 de octubre de 2008. 
Gaceta Parlamentaria, número 4769-XX, 28 de abril de 2017.

Gaceta Parlamentaria, número 3895-III, 29 de octubre de 2013. Resolución Miscelánea Fiscal para 2021.

Legislación extranjera

Constitución Política de la República de Colombia.

Constitución Política de la República del Ecuador. 